\title{
In vitro and in vivo evaluation of cephalosporins for the treatment of Lyme disease
}

\author{
Venkata Raveendra \\ Pothinenil,* \\ Mansi B Parekh',* \\ Mustafeez Mujtaba Babar' \\ Aditya Ambati ${ }^{2}$ \\ Peter Maguire' \\ Mohammed Inayathullah' \\ Kwang-Min Kim' \\ Lobat Tayebi ${ }^{3}$ \\ Hari-Hara SK Potula' \\ Jayakumar Rajadas ${ }^{1,4}$ \\ 'Biomaterials and Advanced Drug \\ Delivery, Stanford Cardiovascular \\ Pharmacology Division, \\ Cardiovascular Institute, School of \\ Medicine, Stanford University, Palo \\ Alto, CA, USA; ${ }^{2}$ Center for Sleep \\ Sciences and Medicine, Department \\ of Psychiatry and Behavioral Sciences, \\ School of Medicine, Stanford \\ University, Palo Alto, CA, USA; \\ ${ }^{3}$ Department of Developmental \\ Sciences, Marquette University School \\ of Dentistry, Milwaukee, WI, USA; \\ ${ }^{4}$ Department of Bioengineering and \\ Therapeutic Sciences, Schools of \\ Pharmacy and Medicine, University \\ of California San Francisco, San \\ Francisco, CA, USA \\ *These authors contributed equally \\ to this work
}

Correspondence: Jayakumar Rajadas 1050 Arastradero Road, Building A, Room AI48, Palo Alto, Stanford University, CA 94304, USA

Tel +l 6507246806

Fax +I 6507244694

Email jayraja@stanford.edu
This article was published in the following Dove Press journal:

Drug Design, Development and Therapy

Background: Lyme disease accounts for $>90 \%$ of all vector-borne disease cases in the United States and affects $\sim 300,000$ persons annually in North America. Though traditional tetracycline antibiotic therapy is generally prescribed for Lyme disease, still $10 \%-20 \%$ of patients treated with current antibiotic therapy still show lingering symptoms.

Methods: In order to identify new drugs, we have evaluated four cephalosporins as a therapeutic alternative to commonly used antibiotics for the treatment of Lyme disease by using microdilution techniques like minimum inhibitory concentration (MIC) and the minimum bactericidal concentration (MBC). We have determined the MIC and MBC of four drugs for three Borrelia burgdorferi s.s strains namely CA8, JLB31 and NP40. The binding studies were performed using in silico analysis.

Results: The MIC order of the four drugs tested is cefoxitin $(1.25 \mu \mathrm{M} / \mathrm{mL})>$ cefamandole $(2.5 \mu \mathrm{M} / \mathrm{mL}),>$ cefuroxime $(5 \mu \mathrm{M} / \mathrm{mL})>$ cefapirin $(10 \mu \mathrm{M} / \mathrm{mL})$. Among the drugs that are tested in this study using in vivo $\mathrm{C} 3 \mathrm{H} / \mathrm{HeN}$ mouse model, cefoxitin effectively kills $\mathrm{B}$. burgdorferi. The in silico analysis revealed that all four cephalosporins studied binds effectively to B. burgdorferi proteins, SecA subunit penicillin-binding protein (PBP) and Outer surface protein E (OspE).

Conclusion: Based on the data obtained, cefoxitin has shown high efficacy killing B. burgdorferi at concentration of $1.25 \mu \mathrm{M} / \mathrm{mL}$. In addition to it, cefoxitin cleared B. burgdorferi infection in $\mathrm{C} 3 \mathrm{H} / \mathrm{HeN}$ mice model at $20 \mathrm{mg} / \mathrm{kg}$.

Keywords: Lyme disease, Borrelia burgdorferi, antimicrobials, penicillin-binding proteins

\section{Introduction}

Lyme disease is the most common zoonotic bacterial disease in North America. More than 300,000 cases of clinical Borreliosis are reported annually in the United States alone. ${ }^{1}$ Though Lyme disease has been prevalent in the colder regions for decades, many new cases have been emerging in the warmer regions of United States where there had been no earlier reports. This increase in the biogeographical distribution of the disease is mainly attributable to the climate change and ability of the pathogenic agent and disease vector to survive in varying biologic and geographical conditions. ${ }^{2,3}$ Among humans, there are a number of clinical presentations of disease including erythema migrans, fever, chills, and muscle and joint pain. ${ }^{4}$ Though these symptoms tend to fade away even if there is no therapeutic intervention, a significant number of untreated patients tend to develop arthritis and persistent myalgia over months to years following the exposure to Borrelia. ${ }^{5}$ More than $10 \%$ of the patients who have been treated for Lyme disease tend to develop symptoms considered typical or even exaggerated presentation of Lyme disease including muscle and joint pain and generalized fatigue. ${ }^{6,7}$ This condition is referred to as posttreatment Lyme disease syndrome. ${ }^{8,9}$

Amoxicillin, doxycycline, cefuroxime axetil, and ceftriaxone are currently considered the drugs of choice for the treatment of the Lyme disease. ${ }^{10}$ Even though the drugs used 
in the current treatment are clinically effective in the majority of cases, treatment failures have been repeatedly reported for most of these compounds. ${ }^{9,11,12}$ Though a number of therapeutic interventions have been used for Lyme disease treatment, yet the reappearance of clinical symptoms of the disease even after the active disease has subsided calls for efforts for identifying novel, potent alternate therapeutic strategies. Some researchers have showed that Borrelia burgdorferi $(\mathrm{Bb})$ cannot be eliminated completely in in vitro cultures. ${ }^{13,14}$ Antibiotic-tolerant Borrelia cells shown in these studies are not resistant mutants but persisters. The currently prescribed drugs used for treating Lyme disease were also not able to eliminate the $\mathrm{Bb}$ completely. ${ }^{13}$

Cephalosporins can be used as an alternative therapy to non-tetracycline antimicrobials. ${ }^{11,15}$ Cephalosporins are safe enough to be used as an alternative treatment for Lyme disease in children and during pregnancy when doxycycline cannot be administered because of detrimental side effects. ${ }^{15,16} \beta$-lactams bind to penicillin-binding proteins (PBPs), which are cytoplasmic membrane-associated enzymes that catalyze terminal reactions in the biosynthesis of peptidoglycan. ${ }^{17,18}$ The enzyme PBPs are targeted by $\beta$-lactams and disrupt various functions like cell growth, cell division, and the maintenance of cell shape. ${ }^{19}$ In $\mathrm{Bb}$, $\beta$-lactam compounds bind to outer surface protein A (OspA), OspB, and OspD, which are considered to be types of PBPs. ${ }^{20}$

This study aims at determining the in vitro susceptibility of Bb s.s. strains to the four cephalosporins. Furthermore, the in vivo efficacy for the candidate drug cefoxitin in $\mathrm{C} 3 \mathrm{H} / \mathrm{HeN}$ mouse model was also determined. The interaction of the four cephalosporins against SecA subunit PBP and OspE was evaluated by in silico analysis. It was found that all the cephalosporins showed high binding affinity to the essential PBP.

\section{Materials and methods}

\section{Bacterial strains and culture}

Three strains of Bb s.s (CA8, JLB31, and NP40) of low passage number were cultured in Barbour-Stoenner-Kelly II (BSK-II) complete medium supplemented with $6 \%$ rabbit serum (Sigma, St Louis, MO, USA). The cultures were grown in $50 \mathrm{~mL}$ falcon tubes (Corning Inc, Corning, NY, USA) at $33^{\circ} \mathrm{C}$ for $3-5$ days in a $5 \% \mathrm{CO}_{2}$ incubator. The BSK-II medium was sterilized through $0.2 \mu \mathrm{m}$ filter units (Millipore, Billerica, MA, USA). The bacterial strains JLB31 and NP40 were generously provided by Dr Linden Hu, Tufts University, Boston, MA, USA.

\section{Minimum inhibitory concentration (MIC) and minimum bactericidal concentration (MBC)}

The MIC and MBC values of the seven antimicrobials were determined by microdilution techniques. MIC was determined by culturing $10^{6} / \mathrm{mL} \mathrm{Bb}$ in BSK-II medium with different concentrations of drugs ranging from 0.31 to $160 \mu \mathrm{M}$. For the MIC, the $1 \mathrm{~mL}$ cultures were grown in 48-well plates in triplicates, wrapped with parafilm, and placed in the incubator for 72 hours at $33^{\circ} \mathrm{C}$ in a humidified $5 \% \mathrm{CO}_{2}$ incubator (Forma Scientific, USA). ${ }^{21,22}$ The MIC was determined by using Bac Titer-Glo microbial cell viability assay. After 72 hours, $100 \mu \mathrm{L}$ of culture was taken from each well and mixed with $100 \mu \mathrm{L}$ of Bac Titer-Glo ${ }^{\circledR}$ reagent (Promega, Madison, WI, USA). Then, the assay was performed according to the manufacturer's instructions. Luminescence was measured on a Flex Station 3 micro plate reader at an integration time of 500 milliseconds. ${ }^{21}$

Conversely, for determining MBC, $10^{6} / \mathrm{mL} \mathrm{Bb}$ cultures grown in BSK-II medium for 72 hours at different drug concentrations were centrifuged and the supernatant was removed. Five hundred microliters of the fresh BSK-II medium was added to the pellet, and resuspended, to which $100 \mu \mathrm{L}$ was added to fresh $1 \mathrm{~mL}$ BSK-II medium and subcultured for 3 weeks. After 3 weeks of incubation period, the samples were observed microscopically for motile spirochetes in the culture. Cell proliferation was assessed using a bacterial counting chamber (Petroff-Hausser Counter, Horsham, PA, USA) by phase contrast microscopy. The procedure was replicated thrice..$^{15,21-23}$

\section{Mice}

Four-week-old female $\mathrm{C} 3 \mathrm{H} / \mathrm{HeN}$ mice were purchased from Charles River Laboratories, Wilmington, MA, USA. All mice were maintained in the pathogen-free animal facility according to animal safety protocol guidelines at Stanford University under the protocol ID APLAC-30105. All experiments were in accordance with the protocols approved by the Institutional Animal Care and Use Committee of Stanford University. The mice were infected intradermally with $0.1 \mathrm{~mL}$ BSK medium containing 100,000 Bb organisms. On the seventh day of infection, the mice were intraperitoneally administered a daily dose of drugs, cefoxitin $(20 \mathrm{mg} / \mathrm{kg})$ and ceftriaxone $(50 \mathrm{mg} / \mathrm{kg})$ for five consecutive days. After 48 hours of the last dose of administering compounds, the mice were killed and their urinary bladders, ears, and hearts were suspended in BSK-II medium. The cultures were evaluated for the presence of motile spirochetes after 21 days using the dark-field microscopy. ${ }^{24}$ If $\mathrm{Bb}$ was observed in any one of the organ in the mice, the animal was considered as infected. The absence of borrelial propagation marked the effectiveness of the treatment in these organisms. 


\section{Molecular docking}

The potential binding affinity and binding modes of the test compounds were determined by performing a molecular docking study. For this purpose, two membrane-associated proteins were selected as mentioned in Table 3 . The protein structures were either retrieved from the Protein Data Bank or determined by ab initio molecular modeling using the Phyre 2 Server. The ligand molecules were prepared using ChemSketch and then docking specifically against the $\mathrm{Bb}$ proteins using AutoDock Vina (v.1.1.2) through a validated docking protocol. ${ }^{18,25}$ The binding affinity of the test compounds to the proteins expressed in $\mathrm{kcal} / \mathrm{mol}$ was obtained. The binding modes were visualized in Discovery Studio 4.0 (Accelrys, USA). ${ }^{26}$

\section{Results}

\section{Determination of MIC and MBC values}

The in vitro susceptibility of these drugs to three strains CA8, JLB31, and NP40 of Bb was evaluated by using BacTiterGlo Assay and microscopy. Based on the MICs obtained the in vitro efficacy of the tested molecules was arranged in the following order for NP40 strain of Bb: cefoxitin (MIC: $1.25 \mu \mathrm{M} / \mathrm{mL}$ ) >cefamandole (MIC: $2.5 \mu \mathrm{M} / \mathrm{mL}$ ), >cefuroxime (MIC: $5 \mu \mathrm{M} / \mathrm{mL}$ ) >cefapirin (MIC: $10 \mu \mathrm{M} / \mathrm{mL}$ ). Also, the in vitro efficacies of tested molecules for other two strains are as follows, for CA8 strain of Bb: cefoxitin (MIC: $0.625 \mu \mathrm{M}$ / $\mathrm{mL}$ ) >cefuroxime (MIC: $1.25 \mu \mathrm{M} / \mathrm{mL}$ ), >cefamandole (MIC: $1.25 \mu \mathrm{M} / \mathrm{mL}$ ) >cefapirin (MIC:5.0 $\mu \mathrm{M} / \mathrm{mL}$ ) and for JLB31 strain of Bb: cefoxitin (MIC: $0.625 \mu \mathrm{M} / \mathrm{mL}$ ) >cefuroxime (MIC: $1.25 \mu \mathrm{M} / \mathrm{mL}$ ), >cefamandole (MIC: $1.25 \mu \mathrm{M} / \mathrm{mL}$ ) $>$ cefapirin (MIC: $2.5 \mu \mathrm{M} / \mathrm{mL}$ ). These results indicate that for the JLB31 and CA8 strains cefoxitin was more effective (MIC: $0.625 \mu \mathrm{M} / \mathrm{mL}$ ) than NP40 strain (MIC: $1.25 \mu \mathrm{M} / \mathrm{mL}$ ). The efficacy of cephalosporins (tested compounds) was determined by BacTiter-Glo Assay as shown in Figure 1. Similarly, we determined the MBC of all the tested cephalosporins. The $\mathrm{MBC}$ values of cefoxitin and cefuroxime were $\leq 10 \mu \mathrm{M}$. Cefamondole showed MBC value $\leq 20 \mu \mathrm{M}$. For cefapirin, the MBC value was very high for NP40 $(>160 \mu \mathrm{M})$ but for other strains it was $\leq 20 \mu \mathrm{M}$. The MIC and MBC values of the tested compounds against the three $\mathrm{Bb}$ strains have been provided in Table 1. Based on these in vitro analyses, cefoxitin was the most potent compound among these cephalosporins tested in our laboratory. We proceeded further for mouse efficacy experiments to provide a better correlation to the clinical conditions.

\section{In vivo testing of drugs in $\mathrm{C} 3 \mathrm{H} / \mathrm{HeN}$ mice}

The efficacies of drugs cefoxitin and gambogic acid were tested in 5-6-week-old female $\mathrm{C} 3 \mathrm{H} / \mathrm{HeN}$ mice. One week

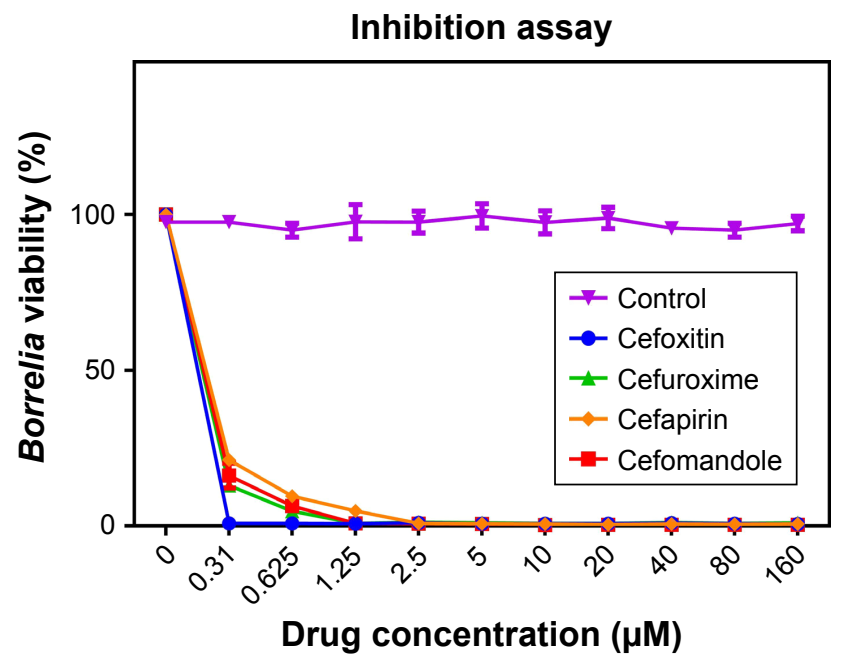

Figure I The efficacy of cephalosporins determined by BacTiter-Glo Assay. Notes: Effect of drugs on Borrelia cell viability was studied with drugs (cefoxitin, cefamandole, cefuroxime, and cefapirin) on CA8 strain. The control has no drug. The results represent mean \pm SD.

after the $\mathrm{Bb}$ infection $\left(1 \times 10^{5}\right.$ of $\mathrm{Bb}$ intradermal route), mice were treated with cefoxitin once a day for 5 days. The mice were killed and the collected organs, ear, urinary bladder, and heart, were placed in BSK-II medium. The tissue samples (ear, urinary bladder, and heart) found no detectable $\mathrm{Bb}$ in all the mice treated with cefoxitin. Cefoxitin cleared infection in all the mice at $20 \mathrm{mg} / \mathrm{kg}$ (Table 2). In ceftriaxone, which was used as a positive control, no borrelial growth was observed. $\mathrm{Bb}$ growth was observed in control saline samples treated with no drug. The efficacy of the drugs tested in vivo has been shown in Table 2.

\section{In silico analysis of cephalosporins binding to PBPs and Osps}

Computational analysis was performed in order to determine the binding potential of the candidate molecules against the $\mathrm{Bb}$ proteins listed in Table 3. Previous studies have identified

Table I MIC and MBC values (in $\mu \mathrm{M}$ ) of the tested compounds on bacterial strains CA8, JLB3I, and NP40

\begin{tabular}{llll}
\hline Compounds & CA8 & JLB3 I & NP40 \\
\hline MIC values & & & \\
Cefamandole & 1.25 & 1.25 & 2.5 \\
Cefapirin & 2.5 & 5 & 10 \\
Cefoxitin & 0.625 & 0.625 & 1.25 \\
Cefuroxime & 1.25 & 2.5 & 5 \\
MBC values & & & \\
Cefamandole & 20 & 40 & 20 \\
Cefapirin & 20 & 10 & $>160$ \\
Cefoxitin & 5 & 5 & 2.5 \\
Cefuroxime & 10 & 20 & 10 \\
\hline
\end{tabular}

Abbreviations: $\mathrm{MBC}$, minimum bactericidal concentration; MIC, minimum inhibitory concentration. 
Table 2 Therapeutic effectiveness of tested compounds in Borrelia burgdorferi-infected $\mathrm{C} 3 \mathrm{H}$ mice

\begin{tabular}{lllll}
\hline Drug name & $\begin{array}{l}\text { Concentration } \\
\text { of drugs }\end{array}$ & $\begin{array}{l}\text { No of } \\
\text { mice } \\
\text { infected }\end{array}$ & $\begin{array}{l}\text { No of } \\
\text { mice } \\
\text { treated }\end{array}$ & $\begin{array}{l}\text { No of mice } \\
\text { cured/no of } \\
\text { mice given }\end{array}$ \\
\hline Cefoxitin & $20 \mathrm{mg} / \mathrm{kg}$ & 3 & 3 & $3 / 3$ \\
Ceftriaxone & $50 \mathrm{mg} / \mathrm{kg}$ & 3 & 3 & $3 / 3$ \\
Saline (control) & & 3 & 3 & $0 / 3$ \\
\hline
\end{tabular}

that $\beta$-lactam antibiotics bind covalently with PBPs and Osps, and they exert their antibacterial effect by blocking the terminal step in cell wall biosynthesis. ${ }^{17,27}$ Based on these previous studies, we performed binding studies between cephalosporin drugs (cefamandole, cefapirin, cefoxitin, and cefuroxime) and SecA subunit PBP and OspE. The binding affinities (docking scores) of PBP and OspE with the four cephalosporins are listed in Table 3.

The molecular docking study revealed that among the drug molecules cefamandole possessed the highest binding affinity $(-8.4 \mathrm{kcal} / \mathrm{mol})$ for the SecA subunit PBP of Bb. The average binding affinity values $(-7.9 \mathrm{kcal} / \mathrm{mol})$ against the test compounds for PBP was significantly higher than the other Borrelia proteins. The cefoxitin that was tested and effective in mice showed a strong binding affinity of $-7.2 \mathrm{kcal} / \mathrm{mol}$ for PBP. It shows a strong hydrogen bonding at amino acid Arg138 of PBP of Borrelia, with an intermolecular distance of less than $5 \AA$ indicating a high preference for this protein. It also forms other interactions like 9 Van der Waals, Pi Stacking, and Alkyl type (Table 4). Other compounds including cefapirin $(-7.9 \mathrm{kcal} / \mathrm{mol})$ and cefuroxime $(-8.2 \mathrm{kcal} / \mathrm{mol})$ also interacted with the drug-binding pockets of the PBP of Borrelia effectively with no statistically significant difference between the values. The linear and spatial arrangement of the four cephalosporins with PBP has been provided in Figure 2. All the interactions predicted between cephalosporins and PBP can be found in Table 4.

\section{Discussion}

We have chosen four cephalosporins (cefoxitin, cefamandole, cefuroxime, and cefapirin) in this study based on the results obtained in the high-throughput screening we have performed. ${ }^{23,28}$ In this study, to our knowledge for the first time, in vitro susceptibility of three Bb s.s. strains (CA8, JLB31, and NP40) against cephalosporins was determined. Microdilution-based methods have been extensively studied in various groups..$^{22}$ Using similar method we tested cephalosporins, and cefoxitin, a second-generation cephalosporin, was found to be one of the most potent drugs that significantly inhibited the cell wall synthesis of Borrelia. ${ }^{15,22}$ Cefamandole, cefapirin, and cefuroxime also effectively inhibited the propagation of the spirochete. The MBC determined for $\mathrm{Bb}$ strain NP40 was higher than $160 \mu \mathrm{M}$ to the antimicrobial agent cefapirin. Some of the potential explanations for a high MBC might be decreased in vitro activity of cefapirin due to the unstable $\beta$-lactam ring, which results in decreasing concentrations during prolonged incubation. Another reason could be that cefapirin might be in bacteriostatic mode in NP40 strain as its MIC is also very high. ${ }^{29}$ Due to its low MIC and $\mathrm{MBC}$ values, cefoxitin was evaluated in vivo in $\mathrm{C} 3 \mathrm{H} /$ $\mathrm{HeN}$ mice model, and was able to eliminate the $\mathrm{Bb}$ infection completely. Cefoxitin is a broad-spectrum antibiotic effective against a wide variety of infections caused by Gram-positive or Gram-negative aerobes as well as by anaerobic bacteria. Cefoxitin is used to treat many infections like intra-abdominal infections, lower respiratory tract infections, urinary tract and gonococal infections, skin and soft-tissue infections, bone and joint infections, and bacteremia. ${ }^{30,31}$ Multiple features are essential for the efficacy of an antibiotic to clear $\mathrm{Bb}$; moreover, there is no clinical guidelines existing for the treatment of chronic borreliosis, and our findings are of immense interest and warrant further study, including in vivo efficacy studies.

A number of cephalosporins were found to be highly effective in eliminating Borrelia in both in vitro and in vivo evaluation. ${ }^{15,32}$ Cephalosporins, much similar to the penicillins and also containing $\beta$-lactam ring, act on the cell membrane of the bacteria and inhibit the peptidoglycan synthesis. ${ }^{17}$ PBPs are one of the essential prokaryotic membrane proteins present in both Gram-positive and Gram-negative bacteria. As in other bacteria, PBPs are cytoplasmic membraneassociated enzymes that catalyze terminal reactions in the biosynthesis of peptidoglycan in Borrelia. $\beta$-lactams are

Table 3 Predicted docking scores of cephalosporins with Borrelia burgdorferi SecA-PBP and OspE

\begin{tabular}{|c|c|c|c|c|c|}
\hline \multirow[t]{2}{*}{ Protein name } & \multirow[t]{2}{*}{ Pdb I.D. } & \multicolumn{4}{|c|}{ Binding affinity (kcal/mol) } \\
\hline & & Cefamandole & Cefapirin & Cefoxitin & Cefuroxime \\
\hline SecA subunit PBP & Ab initio & -8.4 & -7.9 & -7.2 & -8.2 \\
\hline OspE & $2 \mathrm{M} 4 \mathrm{~F}$ & -7.1 & -6.2 & -7.3 & -7.2 \\
\hline
\end{tabular}

Abbreviations: SecA-PBP, subunit penicillin-binding protein; OspE, outer surface protein $\mathrm{E}$. 
Table 4 Interaction of tested cephalosporins with Borrelia burgdorferi SecA-penicillin-binding protein (SecA-PBP)

\begin{tabular}{|c|c|c|c|c|c|}
\hline \multirow[t]{2}{*}{ Compound } & \multirow{2}{*}{$\begin{array}{l}\text { Binding affinity } \\
\text { (kcal/mol) }\end{array}$} & \multicolumn{4}{|l|}{ Types of interaction } \\
\hline & & $\begin{array}{l}\text { Strong hydrogen } \\
\text { bonding }\end{array}$ & Van der Waals & Pi stacking & Alkyl \\
\hline Cefamandole & -8.4 & Tyr193, Ile676 & & \multicolumn{2}{|c|}{ Arg765, Tyr766 } \\
\hline Cefapirin & -7.9 & $\begin{array}{l}\text { Lys374, Arg35I, His358, } \\
\text { Glu372, Thr229 }\end{array}$ & $\begin{array}{l}\text { Gly350, Glu338, Ile339, Leu348, Gly336, } \\
\text { Glu362, Ala78I, Gln359, Ser785 }\end{array}$ & Glu230 & Arg352, Ala370 \\
\hline Cefoxitin & -7.2 & $\operatorname{Arg} 138$ & $\begin{array}{l}\text { Glu524, Ser489, Tyr I34, Phe493, } \\
\text { Val527, Thr515, Lys5I8 }\end{array}$ & \multicolumn{2}{|c|}{ TrpI42, Ala496, lle523 } \\
\hline Cefuroxime & -8.2 & $\begin{array}{l}\text { Ile523, Asn522, Tyr I34, } \\
\text { Glu524 }\end{array}$ & $\begin{array}{l}\text { Phe493, Argl38, Ala492, Thr5I5, } \\
\text { Ala496, Lys518, Gly52I }\end{array}$ & & \\
\hline
\end{tabular}

substrate analogs of the terminal D-Ala-D-Ala residues on the pentapeptide cross-bridges of peptidoglycan subunits, which by binding to PBPs terminate peptidoglycan synthesis. ${ }^{20,27}$ It has been shown in many types of bacteria, as well as in $\mathrm{Bb}$, that compounds with $\beta$-lactam ring bind to PBP. ${ }^{33}$ It has been shown in many types of bacteria, as well as in B. burgdorferi, that compounds with $\beta$-lactam ring bind to $\mathrm{PBP} .{ }^{20}$ Based on these findings, we have done in silico binding studies between four cephalosporin drugs (cefamandole, cefapirin, cefoxitin, and cefuroxime) and two $\mathrm{Bb}$ proteins (secA-PBP
A



C

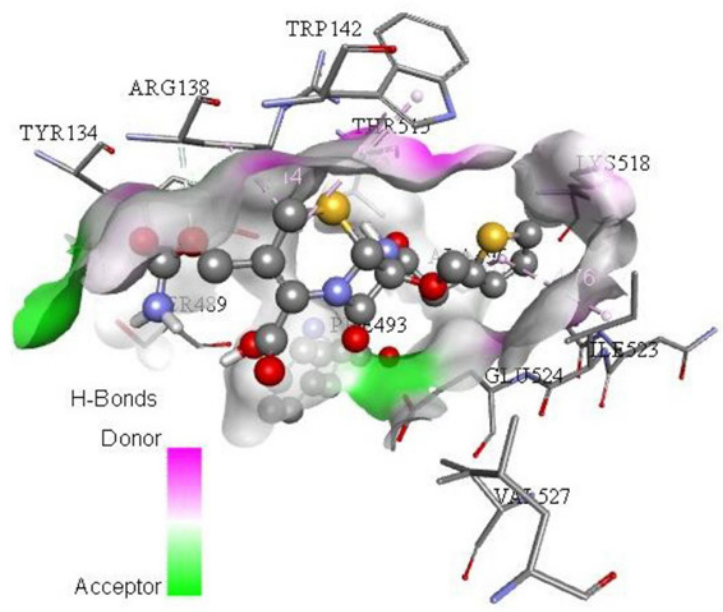

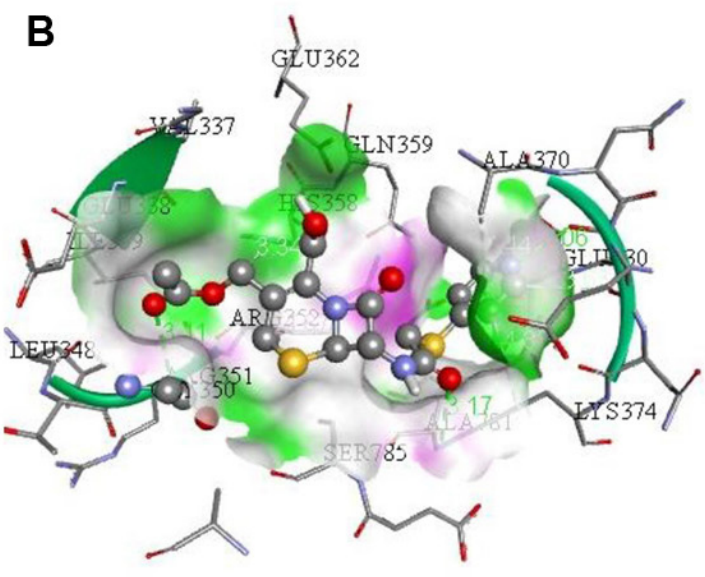

D

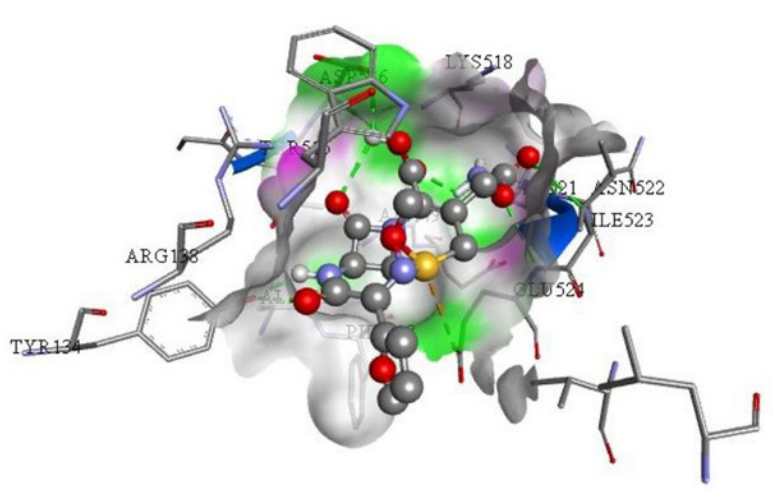

Figure 2 Spatial arrangement of the in silico tested cephalosporins with secA translocase PBP of Borrelia burgdorferi: (A) cefamandole, (B) cefapirin, (C) cefoxitin, and (D) cefuroxime.

Note: The amino acid sequence of secA-PBP (B. burgdorferi B3I) was retrieved from the Uniprot KB (Gene BB_07I8) with a GenBank gene accession number of AE000783 (translation AAC67056.2.).

Abbreviation: PBP, penicillin-binding protein. 
and OspE) shown in Table 3. The in silico analysis we performed showed a high binding preference of cephalosporins to these proteins, further validating the targeting of these essential proteins by the test compounds.

This study gives a new insight into the nature of effective Borrelia antibiotics, and this improved understanding of the compound-protein interactions can be used to help find new targets to aid in the eradication of Borrelia. The preclinical data presented here are beneficial in ascertaining the effectiveness of these molecules and their ability to specifically interact with the bacterial system without possessing any significant adverse effects on the host organism. The outcome of this study can provide input for both mechanistic and translational research, and could be used in establishing clinically viable solutions to Lyme disease.

\section{Conclusion}

We have evaluated the in vitro susceptibility of four drugs to three strains of Bb (CA8, JLB31, and NP40) by using microdilution techniques. Cefoxitin $(1.25 \mu \mathrm{M} / \mathrm{mL})$ has shown low MIC and MBC values. Cefoxitin effectively cleared infection of $\mathrm{Bb}$ in the $\mathrm{C} 3 \mathrm{H} / \mathrm{HeN}$ mice model at $20 \mathrm{mg} / \mathrm{kg}$. By in silico analysis we have shown binding affinities of four cephalosporins with two Bb proteins (PBP and OspE). The SecA subunit PBP has shown higher binding affinity with all the cephalosporins and has potential to study as an effective drug target. We are in the process of performing large-scale studies to prove this potential application of the four cephalosporins evaluated in our study.

\section{Acknowledgments}

This work was accomplished with a generous support from the Bay Area Lyme Foundation. We are indebted to Dr Robert Lane (University of California, Berkley, CA) for his constant support and provision of valuable bacterial strains for the study. We thank Dr Linden Hu and Dr Aurélie Kern, Tufts University, Boston, MA, USA, for providing bacterial strains and help in establishing studies with $\mathrm{C} 3 \mathrm{H} / \mathrm{HeN}$ mice model.

\section{Disclosure}

The authors report no conflicts of interest in this work.

\section{References}

1. Mead PS. Epidemiology of Lyme disease. Infect Dis Clin North Am. 2015; 29(2):187-210.

2. Logiudice K, Ostfeld RS, Schmidt KA, Keesing F. The ecology of infectious disease: effects of host diversity and community composition on Lyme disease risk. Proc Natl Acad Sci U S A. 2003;100(2):567-571.
3. Salkeld DJ, Nieto NC, Carbajales-Dale P, Carbajales-Dale M, Cinkovich SS, Lambin EF. Disease risk \& landscape attributes of tickborne Borrelia pathogens in the San Francisco Bay Area, California. PLoS One. 2015;10(8):e0134812.

4. Aguero-Rosenfeld ME, Wormser GP. Lyme disease: diagnostic issues and controversies. Expert Rev Mol Diagn. 2015;15(1):1-4.

5. Smith AJ, Oertle J, Prato D. Chronic Lyme disease: persistent clinical symptoms related to immune evasion, antibiotic resistance and various defense mechanisms of Borrelia burgdorferi. Open J Med Microbiol. 2014;4(4):252-260.

6. Marques A. Chronic Lyme disease: a review. Infect Dis Clin North Am. 2008;22(2):341-360.

7. Bockenstedt LK, Radolf JD. Xenodiagnosis for posttreatment Lyme disease syndrome: resolving the conundrum or adding to it? Clin Infect Dis. 2014;58(7):946-948.

8. Bockenstedt LK, Gonzalez DG, Haberman AM, Belperron AA. Spirochete antigens persist near cartilage after murine Lyme borreliosis therapy. J Clin Invest. 2012;122(7):2652-2660.

9. Hodzic E, Feng S, Holden K, Freet KJ, Barthold SW. Persistence of Borrelia burgdorferi following antibiotic treatment in mice. Antimicrob Agents Chemother. 2008;52(5):1728-1736.

10. Wormser GP, Dattwyler RJ, Shapiro ED, et al. The clinical assessment, treatment, and prevention of lyme disease, human granulocytic anaplasmosis, and babesiosis: clinical practice guidelines by the Infectious Diseases Society of America. Clin Infect Dis. 2006;43(9):1089-1134.

11. Hunfeld KP, Ruzic-Sabljic E, Norris DE, Kraiczy P, Strle F. In vitro susceptibility testing of Borrelia burgdorferi sensu lato isolates cultured from patients with erythema migrans before and after antimicrobial chemotherapy. Antimicrob Agents Chemother. 2005;49(4):1294-1301.

12. Miklossy J, Kasas S, Zurn AD, Mccall S, Yu S, Mcgeer PL. Persisting atypical and cystic forms of Borrelia burgdorferi and local inflammation in Lyme neuroborreliosis. J Neuroinflammation. 2008;5:40.

13. Sharma B, Brown AV, Matluck NE, Hu LT, Lewis K. Borrelia burgdorferi, the causative agent of Lyme disease, forms drug-tolerant persister cells. Antimicrob Agents Chemother. 2015;59(8):4616-4624.

14. Feng J, Auwaerter PG, Zhang Y. Drug combinations against Borrelia burgdorferi persisters in vitro: eradication achieved by using daptomycin, cefoperazone and doxycycline. PLoS One. 2015;10(3):e0117207.

15. Hunfeld KP, Rödel R, Wichelhaus TA. In vitro activity of eight oral cephalosporins against Borrelia burgdorferi. Int J Antimicrob Agents. 2003;21(4):313-318.

16. Agger WA, Callister SM, Jobe DA. In vitro susceptibilities of Borrelia burgdorferi to five oral cephalosporins and ceftriaxone. Antimicrob Agents Chemother. 1992;36(8):1788-1790.

17. Fontana R, Cornaglia G, Ligozzi M, Mazzariol A. The final goal: penicillin-binding proteins and the target of cephalosporins. Clin Microbiol Infect. 2000;6(Suppl 3):34-40.

18. Trott O, Olson AJ. AutoDock Vina: improving the speed and accuracy of docking with a new scoring function, efficient optimization, and multithreading. J Comput Chem. 2010;31(2):455-461.

19. Weigel LM, Belisle JT, Radolf JD, Norgard MV. Digoxigenin-ampicillin conjugate for detection of penicillin-binding proteins by chemiluminescence. Antimicrob Agents Chemother. 1994;38(2):330-336.

20. Norgard MV, Baker SI, Radolf JD. Chemiluminescent analysis of Borrelia burgdorferi penicillin-binding proteins using ampicillin conjugated to digoxigenin. Microb Pathog. 1995;19(4):257-272.

21. Wagh D, Pothineni VR, Inayathullah M, Liu S, Kim KM, Rajadas J. Borreliacidal activity of Borrelia metal transporter A (BmtA) binding small molecules by manganese transport inhibition. Drug Des Devel Ther. 2015;9:805.

22. Sapi E, Kaur N, Anyanwu S, et al. Evaluation of in-vitro antibiotic susceptibility of different morphological forms of Borrelia burgdorferi. Infect Drug Resist. 2011;4:97-113.

23. Pothineni VR, Wagh D, Babar MM, et al. Identification of new drug candidates against Borrelia burgdorferi using high-throughput screening. Drug Des Devel Ther. 2016;10:1307-1322. 
24. Pavia CS, Wormser GP, Nowakowski J, Cacciapuoti A. Efficacy of an evernimicin (SCH27899) in vitro and in an animal model of Lyme disease. Antimicrob Agents Chemother. 2001;45(3):936-937.

25. Ashraf Z, Rafiq M, Seo SY, Kwon KS, Babar MM, Zaidi NU. Kinetic and in silico studies of novel hydroxy-based thymol analogues as inhibitors of mushroom tyrosinase. Eur J Med Chem. 2015;98: 203-211.

26. Studio D. version 2.5. San Diego, CA, USA: Accelrys Inc; 2009.

27. Kosowska-Shick K, Mcghee PL, Appelbaum PC. Affinity of ceftaroline and other beta-lactams for penicillin-binding proteins from Staphylococcus aureus and Streptococcus pneumoniae. Antimicrob Agents Chemother. 2010;54(5):1670-1677.

28. Pothineni VR, Wagh D, Babar MM, et al. Screening of NCI-DTP library to identify new drug candidates for Borrelia burgdorferi. J Antibiot. 2017;70(3):308-312.
29. Veinović G, Cerar T, Strle F, et al. In vitro susceptibility of European human Borrelia burgdorferi sensu stricto strains to antimicrobial agents. Int J Antimicrob Agents. 2013;41(3):288-291.

30. Stapley EO, Birnbaum J, Miller AK, Wallick H, Hendlin D, Woodruff HB. Cefoxitin and cephamycins: microbiological studies. Rev Infect Dis. 1979;1(1):73-87.

31. Sanders CV, Greenberg RN, Marier RL. Cefamandole and cefoxitin. Ann Intern Med. 1985;103(1):70-78.

32. Johnson RC, Kodner CB, Jurkovich PJ, Collins JJ. Comparative in vitro and in vivo susceptibilities of the Lyme disease spirochete Borrelia burgdorferi to cefuroxime and other antimicrobial agents. Antimicrob Agents Chemother. 1990;34(11):2133-2136.

33. Urban C, Rahal JJ, Dattwyller RJ, Gorevic P, Luft BJ. Penicillinbinding proteins in Borrelia burgdorferi. J Bacteriol. 1990;172(10): 6139-6141.

\section{Publish your work in this journal}

Drug Design, Development and Therapy is an international, peerreviewed open-access journal that spans the spectrum of drug design and development through to clinical applications. Clinical outcomes, patient safety, and programs for the development and effective, safe, and sustained use of medicines are the features of the journal, which has also been accepted for indexing on PubMed Central. The manuscript management system is completely online and includes a very quick and fair peer-review system, which is all easy to use. Visit http://www.dovepress.com/testimonials.php to read real quotes from published authors.

Submit your manuscript here: http://www.dovepress.com/drug-design-development-and-therapy-journal 